\title{
Development and evaluation of an ELISA method for the measurement of kallikrein-related peptidase 5 (KLK5) in human serum
}

\author{
Yanhua Wu, Xiaofei Liu, Yingjian Chen, Chengjin $\mathrm{Hu}^{*}$ \\ Department of Laboratory Medicine, Jinan General Hospital of PLA, Jinan, China \\ Email: ${ }^{*}$ hcj6289@163.com
}

Received 2 September 2013; 2 October 2013; accepted 10 October 2013

Copyright (C) 2013 Yanhua Wu et al. This is an open access article distributed under the Creative Commons Attribution License, which permits unrestricted use, distribution, and reproduction in any medium, provided the original work is properly cited.

\begin{abstract}
Kallikrein-related peptidases (KLKs) have been proposed as potential cancer biomarkers. Kallikreinrelated peptidase 5 (KLK5) is a secreted trypsin-like protease of the KLKs. Until now, detection of KLK5 in both biological fluids and tissues has been described frequently due to the potential of being a new cancer biomarker. Our objective was to prepare KLK5 antibodies and establish an ELISA method for KLK5 to study the possible clinical application of KLK5 as a biomarker for malignancies. In this study, recombinant KLK5 protein was produced and purified using a prokaryotic expression system, and then used as immunogen to generate antibodies. High titers of specific antibodies were measured in serum of rabbits after the forth booster injection. And the titer of the antiserum reached $1: 10^{6}$. We have also generated monoclonal antibodies using hybridoma technology and the titer reached $1: 10^{5}$. The activity of KLK5 antibodies was characterized by Western blot and immunohistochemistry. To quantitatively examine KLK5 in serum samples, we established double antibody sandwich ELISA method using mouse mAb as capture and rabbit pAb as tracer antibody. We have detected KLK5 levels in ovarian cancer serum to ensure that our sandwich ELISA measurement to have high sensitivity and specificity. The ranges of linearity reached by the standard curves of the newly developed ELISA were $0.45 \mathrm{ng} / \mathrm{mL}$ to $125 \mathrm{ng} / \mathrm{mL}$. The detection limit of the method, defined as the concentration of KLK5 can be distinguished, was $0.20 \mathrm{ng} / \mathrm{mL}$. Median serum KLK5 levels were $3.77 \mathrm{ng} / \mathrm{mL}$ and 0.86 $\mathrm{ng} / \mathrm{mL}$ in ovarian cancer patients and normal female, respectively $(P<0.001)$. In conclusion, we prepare anti-KLK5 antibodies and develop the sandwich-type
\end{abstract}

"Corresponding author.
ELISA assay for KLK5. Our preliminary findings prompt that KLK5 may be a new potential biomarker for the diagnosis and prognosis in patients with ovarian.

Keywords: Human Kallikrein 5; Kallikrein-Related Peptidases; Generation of Antibodies; Sandwich ELISA

\section{INTRODUCTION}

The kallikrein family is a group of 15 serine protease genes, which have been mapped on the 19q13.3-4 chromosomal region [1-3]. Each of the family encodes a secreted serine protease, showing significant homologies at both the DNA and the protein level [4]. Human kallikrein-related peptidases are secreted serine protease with trypsin-like or chymotrypsin-like activity. KLKs are translated as inactive pre-proenzymes. Once secreted, preproenzymes are then induced by other KLKs or nonKLK proteases to become active extracellular enzymes [5]. Most of genes are regulated by steroid hormones and abnormally expressed in hormone-related malignancies $[6,7]$. A few members of the family are potential cancer biomarkers for diagnostic and prognostic [8].

The human kallikrein gene 5 (KLK5), initially known as kallikrein-like gene 2 (KLK-L2) or human stratum corneum tryptic enzyme (HSCTE), is a newly identified member of the family $[9,10]$. Kallikrein-related peptidase 5 (KLK5) encoded by KLK5 is a serine protease, under the transcriptional control of estrogens and progestins. KLK5 comprises 293 amino acids and is featured as a pre-pro-enzyme $[9,10]$. Activated KLK5 protein has trypsin-like activity, and its activation depends on the proteolytic cleavage of their N-terminus pro-peptide via autocatalysis or through other KLKs [5]. The KLK5 autoactivation represents an initial process of the KLKs proteolytic cascade, triggering the activation of several other 
KLKs (KLK2, -3, -6, -7, -11, -12 and -14) [11]. The proteolytic activity of KLK5 has already been certified on a large number of ECM components, such as collagens, fibronectin and laminin [12].

KLK5 has been shown to be differentially expressed at the mRNA and the protein levels in many endocrinerelated malignancies, including ovarian, breast, and testicular cancer, and that it has the potential to be a new cancer biomarker [13-16]. The KLK5's presence in biological fluids, such as in the serum of patients with ovarian cancer, has already been measured [17]. High levels were also detected in ascites fluid from metastatic ovarian cancer patients and in ovarian cancer tissue extracts. $67 \%$ of patients with ovarian cancer had elevated KLK5 levels in serum [16]. KLK5 is significantly elevated in ovarian cancer tissues compared with low-malignantpotential (LMP) tumors. High KLK5 tumor tissue levels are associated with advanced stage of the disease and significantly shorter progression-free survival and overall survival. The present study focus on evaluating the KLK5 as new serum biomarker in ovarian cancer, which may serve as a screening tool, may allow assessment of prognosis in patients with ovarian cancer and may be as a potential new target for therapy $[13,18]$.

We hypothesize that this secreted protein may have applications as a biomarker for cancer, such as ovarian cancer. So highly sensitive and specific ELISA assay must be established for these possibilities to be examined. In this paper, we prepare KLK5 antibodies and develop a sensitive and specific sandwich ELISA for KLK5, to analysis the presence of KLK5 in serum samples and to study the possible clinical utility of KLK5 as a biomarker for malignancies.

\section{MATERIALS AND METHODS}

\subsection{Clinical Samples}

The study group consisted of 40 patients with ovarian cancer who underwent surgery for primary ovarian cancer at Jinan Military General Hospital between October 2009 and May 2011 and 40 healthy control women as well. Patients' mean age was $51.3 \pm 3.6$, with a range of 22 - 80 years. Samples were collected preoperatively and no chemotherapy or radiotherapy had been administered before surgery. Sera were obtained and preserved at $-80^{\circ} \mathrm{C}$ until the time of KLK5 measurements. The patients' preoperative serum CA125 levels were taken from the patients' data sheets. Conventional sections were selected for titration of the antibodies and for comparison of staining results between tumor and corresponding tumor-free areas within the same specimen.

\subsection{Chemicals and Instruments}

Isopropy- $\beta$-D-thiogalactoside (IPTG), 10 -Deacetylbac- catin III (DAB) and bovine serum albumin (BSA) were purchased from Sigma (USA). Ni-NTA-His affinity column and Protein A purification Kit were purchased from Qiangen (USA) and Thermo, respectively. goat antirabbit IgG alkaline phosphatase conjugate and mouse anti-his antibody were purchased from Tiangen (China). ELISA experiments were performed in 96-microwell plates (Corning).

\subsection{Production and Purification of Recombinant KLK5 Protein}

The pET28b vector containing the mature KLK5 cDNA sequence was introduced into the yeast strains $E$. coli BL21 and then a stable clone was selected from the strain. A culture was grown in $\mathrm{LB}$ medium at $28^{\circ} \mathrm{C}$ shaking incubator $\left(250 \mathrm{rpm}\right.$ ) until the $\mathrm{OD}_{600}$ was $0.6-1.0$, at which point IPTG $(1.0 \mathrm{mM}$, final) was added to induce protein expression.

Because the KLK5 protein is predicted to be a secreted protein, recombinant KLK5 was purified from yeast split supernatants by Ni-NTA affinity chromatography according to the manufacturer's guidelines (Qiangen, USA). The purified material was then separated by $12 \%$ SDSPAGE and stained with Coomassie Blue to assess its purity and its molecular mass. The protein concentration of the purified KLK5 was determined by the bicinchoninic acid method, which uses BSA as calibrator (Sigma, USA). A specific anti-his antibody was used to monitor KLK5 production by Western blot analysis (Tiangen, China).

\subsection{Production of Polyclonal Antibodies against KLK5}

Four adult male New Zealand white rabbits with body weights of approximately $2 \mathrm{Kg}$ were prepared from medical center of Shandong University. The purified recombinant KLK5 protein, emulsified with the same dosage of Freund's complete adjuvant, was used as immunogen to develop antibodies. $500 \mu \mathrm{g}$ KLK5 was injected into each animal subcutaneously. Two weeks after the initial immunization, the ordinal booster was taken every 10 days. Before immunization, blood was obtained from each animal to prepare non-immune serum for negative control. The antibody titer was tested with indirect ELISA after the last booster and reached $1: 10^{6}$. The antiserum was further purified using Protein A purification Kit following the manufacturer's protocol (Qiangen, USA).

\subsection{Prepare of Monoclonal Antibodies}

Hybridoma technology was employed to prepare antiKLK5 monoclonal antibodies. Four 6-week-old adult BALB/c mice were purchased by Shandong University School of Medicine. A mouse with an antibody titer 
greater than 1:5000 was selected for preparation for hybridoma cell lines. Cell fusion of $\mathrm{Sp} 2 / 0$ cells and spleen lymphocytes from the immunized mouse was conducted by $50 \%(\mathrm{w} / \mathrm{v}) \mathrm{PEG} 4000$, with a ratio of $1: 5$ of $\mathrm{Sp} 2 / 0$ and spleen cells. The fusion cell were selected in HAT (Sigma, USA) medium for 7 days and detected by indirect ELISA. The positive hybridomas were subsequently cloned three times with a limiting dilution procedure. Then the cloned hybridomas were intraperitoneally injected into BALB/c mice to prepare ascites. Indirect ELISA showed that the collected ascites contained a high titer of KLK5 antibody, reaching $1: 10^{5}$.

\subsection{Western Blot Analysis}

To demonstrate specificity of antibodies, samples of recombinant KLK5 was subjected to $12 \%$ SDS-PAGE, and separated proteins were then transferred onto nitrocellulose filter (NC) membranes (BioTrace, Pall, USA) using a semi-dry transfer device. Subsequently, membranes were blocked with 5\% skim milk powder in PBS-0.1\% Tween-20 buffer ( $\mathrm{pH} 7.4$ ) overnight at $4^{\circ} \mathrm{C}$. Then, blots were incubated for $1 \mathrm{~h}$ at room temperature with the respective antibodies diluted 1:10,000 in PBS-0.1\% Tween20 buffer, followed by three washes, 5 min each, in PBS$0.1 \%$ Tween-20 buffer at room temperature. Binding of the antibodies to the target protein was visualized by incubation of the membrane with HRP-conjugated goat anti-rat or sheep anti-mouse IgG (Tiangen, China) containing 5\% skim milk powder, followed by HRP-DAB (Tiangen, China). For determination of the relative molecular mass of the various KLK proteins, the pre-stained Protein Marker (Fermentas, Canada) was employed.

\subsection{Immunohistochemisty}

The tissue sections were dewaxed, rehydrated, and treated for antigen retrieval by pressure cooking $\left(5 \mathrm{~min}, 120^{\circ} \mathrm{C}\right.$, $0.1 \mathrm{M}$ citrate buffer, $\mathrm{pH}$ 6.0). After several washes with Tris-buffered saline (TBS, $\mathrm{pH} 7.6$ ), $3 \% \mathrm{H}_{2} \mathrm{O}_{2}$ in TBS was applied for $10 \mathrm{~min}$ at room temperature to block endogenous peroxidase activity. Normal goat serum diluted 1:100 in TBS was applied for $10 \mathrm{~min}$ at room temperature to block nonspecific antibody binding. Subsequently, primary antibodies (pAb or $\mathrm{mAb}$ ) were allowed to react overnight at $4{ }^{\circ} \mathrm{C}$, followed by incubation with biotinylated HRP-labeled goat anti-rat or sheep anti-mouse IgG (Tiangen, China) for $15 \mathrm{~min}$ at room temperature. After several washes, the Vectastain Elite ABC-reagent (Vector Laboratories) was applied for $50 \mathrm{~min}$ at room temperature and the washing steps were repeated. The peroxidase reaction was developed with 3,39-diami-nobenzidine (DAB, Tiangen, China) for $10 \mathrm{~min}$ at room temperature in the dark. Finally, counterstaining of sections was performed with hematoxylin. As a negative control, the primary antibody was omitted and replaced by PBS.

\subsection{Establishment of KLK5 ELISA Method}

Purified polyclonal antibodies were labeled with horseradish peroxidase. A double sandwich-type ELISA was developed as follows: white polystyrene microtiter plates (Corning, USA) were coated with $100 \mu \mathrm{L}$ anti-KLK5 $\mathrm{mAb}(7.5 \mu \mathrm{g} / \mathrm{mL})$ and held overnight at $4^{\circ} \mathrm{C}$. The plates were then blocked with $4 \% \mathrm{BSA}$ for $2 \mathrm{~h}$ at $37^{\circ} \mathrm{C}$ and washed six times with the washing buffer $[0.5 \mathrm{~g} /$ liter Tween 20 in 0.01 M PBS buffer] (pH 7.4).

The highest standard solution was prepared at 125 $\mathrm{ng} / \mathrm{mL}$ in PBS ( $\mathrm{pH} 7.8$ ). The other standard solutions were prepared from the highest standard solution to concentrations of $62.5,31.2,15.6,7.8,3.9$ and $0 \mathrm{ng} / \mathrm{mL}$. Calibrators or samples were pipette into the microtiter wells $(100 \mu \mathrm{L} /$ well $)$ and incubated at $37^{\circ} \mathrm{C}$ for $1 \mathrm{~h}$ shaking; the plates were then washed with washing buffer six times. Subsequently, $100 \mu \mathrm{L}$ of rabbit anti-KLK5 antibodies conjugated to HRP (1 mg/mL) diluted 1000-fold in PBS were then added and incubated at $37^{\circ} \mathrm{C}$ for 40 min. After the wells were washed six times with PBST, $100 \mu \mathrm{L}$ of TMB substrate was added per well and the plates were held at $37^{\circ} \mathrm{C}$ for $10 \mathrm{~min}$. Absorbance was measured at $450 \mathrm{~nm}$ after quenching the wells with 50 $\mu \mathrm{L}$ of $2 \mathrm{~mol} / \mathrm{L} \mathrm{H}_{2} \mathrm{SO}_{4}$.

Recombinant KLK5 was used to generate the calibration curve. The detection limit, defined as the concentration of KLK5 corresponding to the absorbance of the zero calibrator plus 3SDs. The cross reaction of other homologous proteins were investigated using purified recombinant KLKs. To assess the recovery of the assay, within-run (3 replicates) and between-run (3 replicates) variation were assessed at various KLK5 concentrations.

\subsection{Statistical Analysis}

Values obtained from our ELISA assays were given as mean, SD, and range. The analysis of the differences in the two groups of patients was performed with the nonparametric Mann-Whitney U test. Results were evaluated using SPSS 17.0. The results were considered statistically significant when $P<0.05$. Receiver operating characteristic (ROC) curve was constructed by Sigmaplot 11.0 .

\section{RESULT}

\subsection{Expression and Purification of the Recombinant KLK5 (His-Tag) Protein}

The recombinant expression plasmid (pET28b(+)-KLK5) was transformed into E. coli BL21 to prepare recombinant proteins. The highest amount of recombinant proteins was obtained when the IPTG inducer was added in. 
Fusion proteins were mainly expressed in the form of solubility protein in supernatant of lysates. The lysates of the transformed E. coli strain BL21 were subsequently purified by the affinity chromatography of Ni-NTA agarose. As expected, SDS-PAGE revealed a $28 \mathrm{KD}$ band in the eluted fraction, target protein was expressed, as in Figure 1(A). To examine this further, the purified protein was further confirmed by Western blot using antiHis monoclonal antibody. Western blot demonstrated a specific reactive fragment at the expected mobilizing position, the His-KLK5 was expressed at $28 \mathrm{KD}$, as in Figure 1(B).

\subsection{Preparation and Characterization of Anti-KLK5 Antibodies}

Purified KLK5 protein was injected into rabbits and mice as described in "Materials and Methods" to generate antibodies. Results of indirect ELISA showed that high titers of specific antibodies are detected in serum of rabbits after the fourth booster. About $40 \mathrm{~mL}$ antiserum per rabbit was harvested and centrifuged. The purified polyclonal antibody had a titer of approximately $1: 10^{6}$.

After cell fusion and selection with HAT medium culture, there were 18 wells containing growing cell clones, one stable hybridoma designated as $3 \mathrm{~B}_{4}$ was obtained after the third subclone. The titer of the ascitic fluid primed by specific hybridoma was $1: 10^{5}$. IgG subtyping analyses showed that $3 \mathrm{~B}_{4}$ belonged to $\operatorname{IgG} 2 \mathrm{~b}$ with a kappa light chain.

The purified anti-KLK5 antibodies were identified by ELISA, Western blot, and immunohistochemical methods. The results showed that the prepared antibodies were specific to KLK5 with good specificity and antibody titer.

Western blot of before and after purified antibodies showed a single protein band of about $50 \mathrm{kDa}$ with puri-
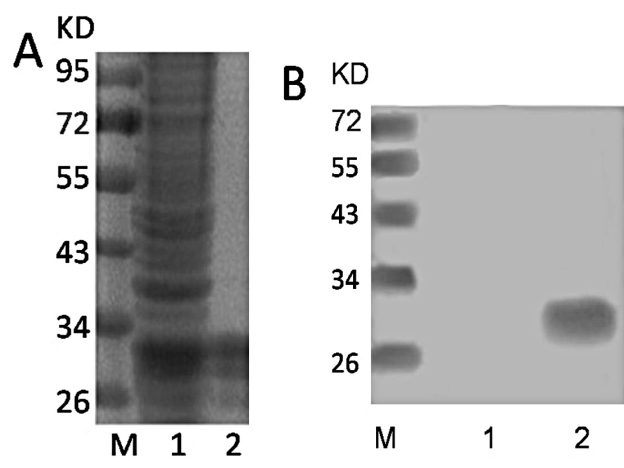

Figure 1. (A) The protein profile of before and after purified in $12 \%$ SDS-PAGE. M: Protein marker; lane 1: Before purified; lane 2: After purified; (B) Western blotting analysis of His-KLK5. $\mathrm{M}$ : Protein marker; lane 1: PBS as negative control; 2: purified his-tagged KLK5. fied antibodies, as in Figures 2(A) and (B). Western blotting analysis of the specificity of antibodies showed that only the recombinant protein was detected by the antibody compared to the extract of E. coli BL21 which were not transformed (negative control), corresponded to amass of approximately 28KD, as in Figures 2(C) and (D).

The tissues sections were immunostained with the anti-KLK5 polyclonal or monoclonal antibody, diluted 200 -fold in PBS. KLK5 protein is expressed very weakly in normal adjacent tissue cyst, as in Figures 3(A) and (C), but distinctly expressed in primary serous ovarian cancer tissue cytoplasm, as in Figures 3(B) and (D).

\subsection{Establishment of ELISA Assay}

We used mouse $\mathrm{mAb}$ as capture and rabbit pAb as tracer antibody to establish a double antibody sandwich ELISA method. We have further carefully optimized the concentration of antibodies used, the diluents, and incubation times of the various assay steps. The HRP-pAb and coating $\mathrm{mAb}$ were optimized for concentration by running the assays under various combinations. Optimal conditions were selected based on the lowest achievable detection limit and best assay linearity and dynamic range. The final conditions are described in the experimental section.

A typical calibration curve of the proposed KLK5 assay is drawn in Figure 4. It shown satisfactory linear correlation, the range was from $0.45 \mathrm{ng} / \mathrm{mL}$ to $125 \mathrm{ng} / \mathrm{mL}$. According to the calibration curve, the detection limit
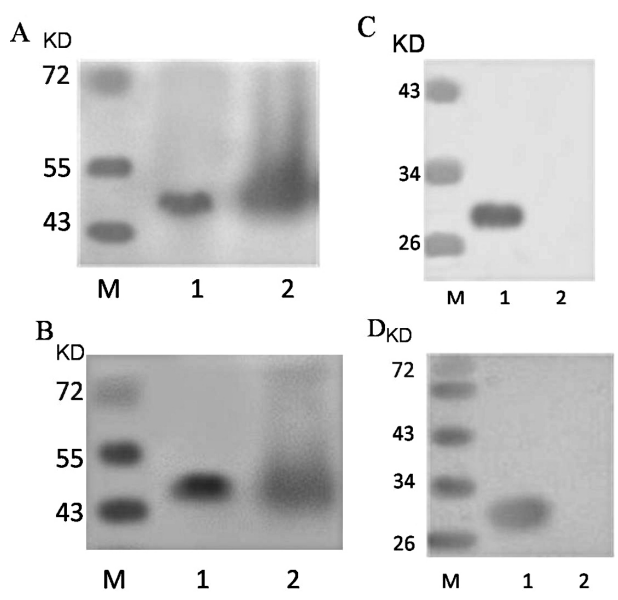

Figure 2. Expression and purified of KLK5 antibodies. (A) lane 1: purified pAb; lane 2: rabbit serum after the last booster; (B) lane 1: purified $\mathrm{mAb}$; lane 2: ascitic fluid of BALB/c mice; (C) lane 1: recombinant His-KLK5 protein; lane 2: extract of $E$. coli which were not transformed (negative control); western blot using purified $\mathrm{pAb}$ at 1:1000 dilution; (D) lane 1: recombinant His-KLK5 protein; lane 2: extract of E. coli which were not transformed (negative control); western blot using purified $\mathrm{mAb}$ at 1:1000 dilution. 

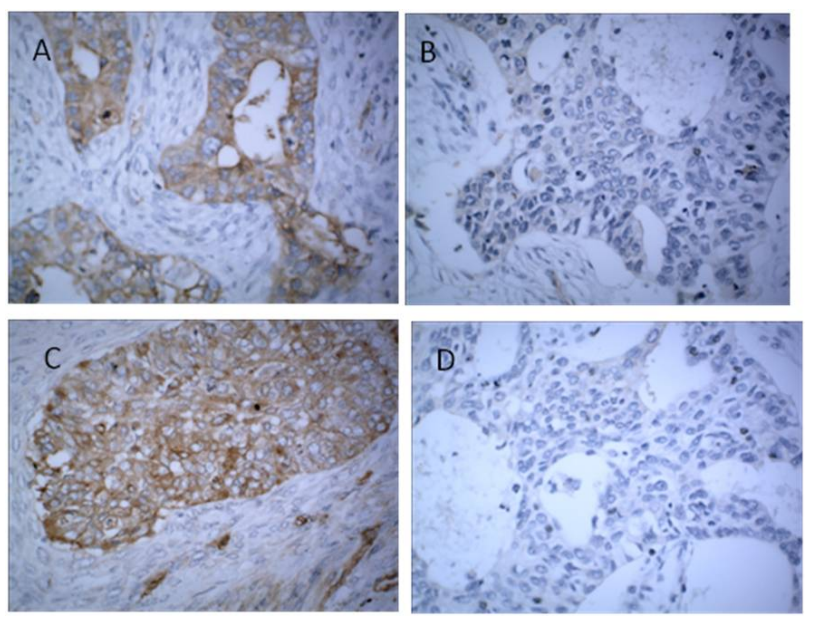

Figure 3. Immunohistochemical staining for presence of kallikrein-related peptidase 5 (KLK5) in normal and malignant tumor tissues. Representative tissues of primary ovarian cancer (serous cystadenocarcinoma of the ovary), as in (A) and (C), and normal adjacent tissues as in (B) and (D); were stained with hematoxylin-eosin. All photomicrographs were taken at $200 \times$. KLK5: brown color; nuclei were counterstained with hematoxylin (blue color). Immunohistochemical localization of KLK5 shows staining in the cytoplasm of ovarian cancer and gastric cancer, as in (A) and (C), but KLK5 protein expression is almost absent in the normal tissue, as in (B) and (D).

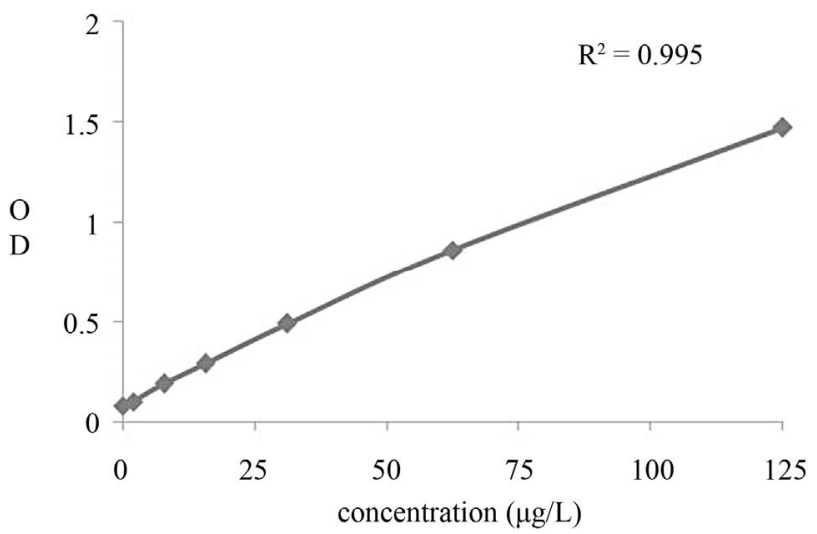

Figure 4. Calibration curve of the newly developed KLK5 ELISA assay. KLK5 standard substance was serially diluted with $0.01 \mathrm{M}$ PBS, and $100 \mu \mathrm{l}$ of the solution was added to each well of anti-KLK5 monoclonal antibody-coated ELISA plates. Then, the bound KLK5 was detected by the HRP-conjugated polyclonal antibody. The results were indicated as the mean absorbance at $450 \mathrm{~nm}$ of triplicate wells.

was $0.20 \mathrm{ng} / \mathrm{mL}$. Three samples of different KLK5 concentrations were detected using the new method to assess its recovery. The results showed that the intra-assay and inter-assay coefficients of variation (CVs) are between $2.4 \%$ and $4.2 \%$ and between $5.2 \%$ and $6.8 \%$, respectively. Because KLK5 is a member of the KLK family, it shares significant amino acid homology with other KLKs. To demonstrate that there is no interference from these homologous proteins, the cross-reactivities of recombi- ant KLK6, BSA and PBS were examined. All other proteins produced no measurable readings, even at concentrations higher than that of KLK5. There was no crossreaction between other KLKs. The data shown this immunoassay can specificity discriminate KLK5 from other homologous proteins. Results above all indicated that the ELISA method could be used as a high throughput, quantitative monitoring tool for human cancer.

\subsection{Expression of KLK5 in Ovarian Cancer Serum}

The expression of KLK5 in serum of cancers was researched with the developed immunoassay to evaluate and analyses clinical application. KLK5 was detected in ovarian cancer (40) and normal female (40). The results showed that KLK5 is significantly elevated in serum of ovarian cancer patients $(n=40)$ compared with normal female ( $\mathrm{n}=40$, with one sample below detection limit). In 27 of 40 ovarian cancer serum samples were positive for KLK5 with a cutoff value $1.76 \mathrm{ng} / \mathrm{mL}$. The KLK5 serum concentration in ovarian cancer patients $(3.77 \pm$ 1.47) $\mathrm{ng} / \mathrm{mL}$ were significantly higher than those in normal female $(0.86 \pm 0.45) \mathrm{ng} / \mathrm{mL}(P<0.01)$, as in Table 1.

ROC curve analysis revealed the significant and the independent value of the KLK5 expression, for the discrimination of the malignant from the normal individuals, as in Figure 5. Moreover, there was no correlation between KLK5 expression levels and CA125. This preliminary findings prompted that KLK5 may be an independent potential biomarker for the diagnosis and prognosis in patients with ovarian.

The sensitivity of CA125 alone to detect total ovarian cancer was $57.5 \%$, while KLK5 showed a sensitivity level comparable to CA125 (67.5\% vs. $57.5 \%$, respectively). The sensitivity to detect ovarian cancer improved to $75 \%$ when CA125 and KLK5 were used in combination. These results show a combined panel KLK5 and CA125 is a more sensitive test to detect ovarian cancer than CA125 alone, indicating assaying for kallikreinrelated peptidases, in addition to CA125, could provide a significant advantage to detect ovarian cancer.

\section{DISCUSSION}

New methods and biomarkers with improved sensitivity and specificity are urgent needed for early detection and diagnosis of cancer, and in recent years, some new promising serum biomarkers have been identified, including Kallikrein-related peptidases. KLK5 is a newly identified member of the KLKs family. It is known to play an important role in skin desquamation [19-22]. The highest concentrations of KLK5 were found in adult and fetal skin. They found moderate KLK5 concentrations in breast 
Table 1. Descriptive statistics of KLK5 expression in serum.

\begin{tabular}{cccccccc}
\hline \multirow{2}{*}{ Variables } & \multirow{2}{*}{$\mathrm{N}^{\mathrm{a}}$} & \multirow{2}{*}{ Range } & \multicolumn{3}{c}{ Percentile } & \multirow{2}{*}{ Mean $\pm \mathrm{SE}^{\mathrm{b}}$} & $P$ \\
\cline { 4 - 6 } & & & $25 \%$ & $50 \%$ & $75 \%$ & & \multirow{2}{*}{$P^{*}<0.01$} \\
\hline Normal female & 40 & $0.44-3.45$ & 0.71 & 0.85 & 1.92 & $0.86 \pm 0.45$ \\
Ovarian cancer & 40 & $0.71-7.76$ & 3.14 & 3.51 & 4.42 & $3.77 \pm 1.47$ \\
\hline
\end{tabular}

${ }^{\mathrm{a}}$ Number of samples; ${ }^{\mathrm{b}}$ Standard error; $P^{*}$ : Ovarian cancer $v s$. normal female; The $P$ value was calculated using the Mann-Whitney $U$ test.

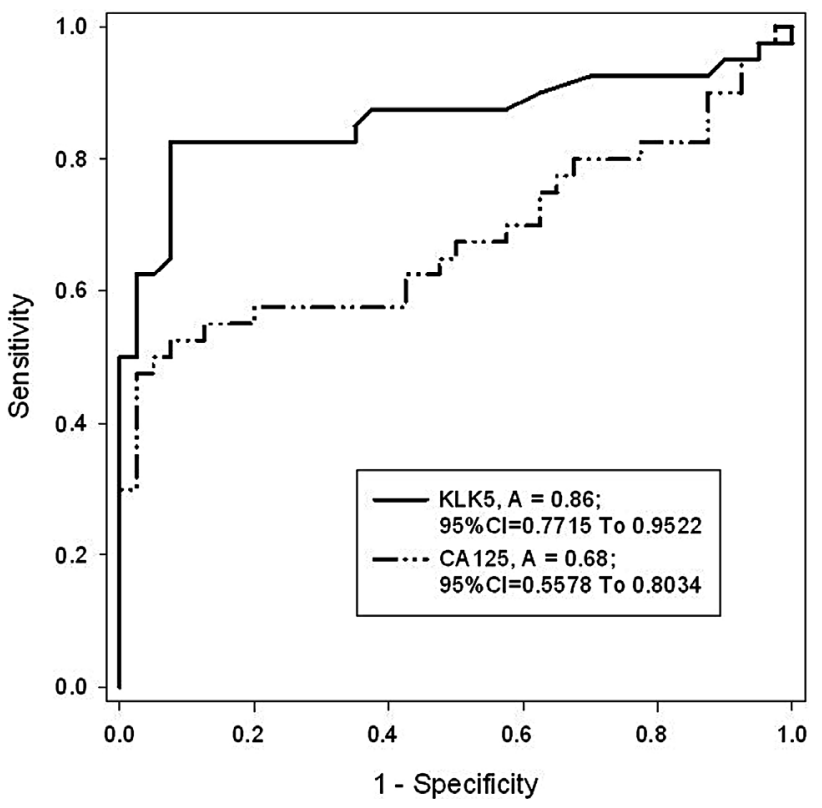

Figure 5. ROC analysis of the KLK5 expression quantification in ovarian cancer prediction. ROC curve comparing the distribution of serum levels of KLK5 and CA125 in patients with ovarian carcinoma versus healthy controls. The $P$ value was 0.01 and the difference was statistical significance. The area under the ROC curves (AUC) was analyzed by Hanley and McNeil method.

and testis and low concentrations in lung [17]. Several studies have demonstrated that KLK5 is implicated in the development of the tumor and disease, but the detailed molecular mechanism of KLK5 function remains to be elucidated.

In our study, recombinant KLK5 protein was produced and then was injected into rabbits to generate polyclonal antibodies, and the hybridoma technique was employed to prepare monoclonal antibody. The KLK5 protein was examined and further confirmed by Western blot using anti-His monoclonal antibody. The purity and specificity of antibodies then were detected Western blot. It had reported that KLK5 was significantly elevated in ovarian cancer tissues and serum, so the activity of antibodies was further analysis with immunohistochemical in ovarian cancer tissues. Western blot and IHC show that the prepared antibodies could efficiently bind with KLK5. Four cell lines of hybridomas that secreted KLK5 antibody were obtained using recombinant His-KLK5 as the immunogen. Theoretically, mAb could react with only specific KLK5 antigenic determinants. It was confirmed that antibodies could recognize the recombinant KLK5 proteins and there was no cross-reaction with KLK6 using ELISA.

Enzyme-linked immunosorbent assay as detective systems for antigen or antibody recognition have attracted extensive attention because of their potential utility as specific, simple and direct detection techniques. This study provides a novel, sensitive and convenient method. The chosen antibodies were further purification and conjugation with the HRP, and it is thus a sensitive and specific method for developing convenient ELISA method. It has no cross-reaction with other KLKs. Yousef has reported the development of the first immunofluorometric assay for KLK5 and described the distribution of KLK5 in biological fluids and tissue extracts. They adopted a sandwich-type assay configuration (ELISA) in which the capture antibody was generated in mice, and the detection antibody was generated in rabbits. The assay configuration does not necessitate any prior antibody purification. Both the capture antibody and the detection antibody were polyclonal antibodies [16].

As we know, there is highly homology between KLKs members. To demonstrate that there is no interference from these homologous proteins, the cross-reactivities of recombinant KLK6, no-correlation protein BSA and PBS were examined. All other proteins produced no measureable readings, even at concentrations higher than that of KLK5.

Presently, ovarian cancer is diagnosed using high resolution computer-aided tomography (CT) or transvaginal sonography prompted by serum tests with elevated CA125 levels [23]. But it is not useful in general population screening for early stage ovarian cancer as $40 \%-50 \%$ of Stage I/II ovarian cancers are CA125 negative [24].

In our study, sera from ovarian cancer patients were analyzed for content of CA 125, as well as KLK5. We found KLK5 elevated in seven of 17 patients with CA125 negative tumors serum. Within our cohort, CA125 was elevated in $57.5 \%$ of the primary ovarian cancers. By combining KLK5 with CA125, an additional seven ovarian cancer patients were detected. The use of these two additional markers improved overall sensitivity from $57.5 \%$ to $75 \%$.

Kallikrein-related peptidases represent potential biomarkers for ovarian cancer diagnosis, prognosis, and disease monitoring [25]. Here, we provide evidence of se- 
rum KLK5 protein elevation in a subset of patients with ovarian cancer, demonstrating that our results are in agreement with those reported by others [26,27]. We have also demonstrated that level of KLK5 and the established ovarian cancer tumor marker CA 125 did not correlate.

In conclusion, our study established a specific immunodetection method and suggested the presence of KLK5 in serum. Our data supported the finding that most of ovarian cancer patients release significant amounts of KLK5 into serum but KLK5 is low in serum of patients with colorectal cancer. The relevance of the differential expression is still elusive and needs to be addressed in further studies.

\section{REFERENCES}

[1] Yousef, G.M. and Diamandis, E.P. (2001) The new human tissue kallikrein gene family: Structure, function, and association to disease. Endocrine Reviews, 22, 184204. http://dx.doi.org/10.1210/er.22.2.184

[2] Yousef, G.M., Chang, A., Scorilas, A. and Diamandis, E.P. (2000) Genomic organization of the human kallikrein gene family on chromosome 19q13.3-q13.4. Biochemical and Biophysical Research Communications, 1, 125-133. http://dx.doi.org/10.1006/bbrc.2000.3448

[3] Yousef, G.M., Luo, L.Y. and Diamandis, E.P. (1999) Identification of novel human hallidrein-like genes on chromosome 19q13.3-19q13.4. Anticancer Research, 19, 2843-2852.

[4] Yousef, G.M. and Diamandis, E.P. (2000) Human kallikreins: Common structural features, sequence analysis and evolution. Current Genomics, 4, 147-165. http://dx.doi.org/10.2174/1389202033350074

[5] Borgono, C.A., Michael, I.P. and Diamandis, E.P. (2004) Human tissue kallikreins: Physiologic roles and applications in cancer. Molecular Cancer Research, 2, 257-280.

[6] Paliouras, M. and Diamandis, E.P. (2006) The kallikrein world: An update on the human tissue kallikreins. Biological Chemistry, 6, 643-652.

[7] Paliouras, M. and Diamandis, E.P. (2007) Coordinated steroid hormone-dependent and independent expression of multiple kallikreins in breast cancer cell lines. Breast Cancer Research and Treatment, 1, 7-18. http://dx.doi.org/10.1007/s10549-006-9312-y

[8] Diamandis, E.P., Yousef, G.M., Luo, L.Y., Magklara, A. and Obiezu, C.V. (2000) The new human kallikrein gene family: Implications in carcinogenesis. Trends in Endocrinology \& Metabolism, 2, 54-60. http://dx.doi.org/10.1016/S1043-2760(99)00225-8

[9] Yousef, G.M. and Diamandis, E.P. (1999) The new kallikrein-like gene, KLK-L2. Molecular characterization, mapping, tissue expression, and hormonal regulation. Journal of Biological Chemistry, 53, 37511-37516. http://dx.doi.org/10.1074/jbc.274.53.37511

[10] Brattsand, M. and Egelrud, T. (1999) Purification, molecular cloning, and expression of a human stratum cor- neum trypsin-like serine protease with possible function in desquamation. Journal of Biological Chemistry, 42, 30033-30040. http://dx.doi.org/10.1074/jbc.274.42.30033

[11] Michael, I.P., Pampalakis, G., Mikolajczyk, S.D., Malm, J., Sotiropoulou, G. and Diamandis, E.P. (2006) Human tissue kallikrein 5 is a member of a proteolytic cascade pathway involved in seminal clot liquefaction and potentially in prostate cancer progression. Journal of Biological Chemistry, 18, 12743-12750. http://dx.doi.org/10.1074/jbc.M600326200

[12] Michael, I.P., Sotiropoulou, G., Pampalakis, G., Magklara, A., Ghosh, M., Wasney, G. and Diamandis, E.P. (2005) Biochemical and enzymatic characterization of human kallikrein 5 (hK5), a novel serine protease potentially involved in cancer progression. Journal of Biological Chemistry, 15, 14628-14635. http://dx.doi.org/10.1074/jbc.M408132200

[13] Kim, H., Scorilas, A., Katsaros, D., Yousef, G.M., Massobrio, M., Fracchioli, S., Piccinno, R., Gordini, G. and Diamandis, E.P. (2001) Human kallikrein gene 5 (KLK5) expression is an indicator of poor prognosis in ovarian cancer. British Journal of Cancer, 5, 643-650. http://dx.doi.org/10.1054/bjoc.2000.1649

[14] Yousef, G.M., Scorilas, A., Kyriakopoulou, L.G., Rendl, L., Diamandis, M., Ponzone, R., Biglia, N., Giai, M., Roagna, R., Sismondi, P. and Diamandis, E.P. (2002) Human kallikrein gene 5 (KLK5) expression by quantitative PCR: An independent indicator of poor prognosis in breast cancer. Clinical Chemistry, 8, 1241-1250.

[15] Yousef, G.M., Obiezu, C., Jung, K., Stephan, C., Scorilas, A. and Diamandis, E.P. (2002) Differetial expression of kallikrein gene 5 (KLK5) in cancerous and normal testicular tissues. Urology, 4, 714-718. http://dx.doi.org/10.1016/S0090-4295(02)01811-3

[16] Yousef, G.M., Polymeris, M.E., Grass, L., Soosaipillai, A., Chan, P.C., Scorilas, A., Borgoño, C., Harbeck, N., Schmalfeldt, B., Dorn, J., Schmitt, M. and Diamandis, E.P. (2003) Human Kallikrein 5: A potential novel serum biomarker for breast and ovarian cancer. Cancer Research, 14, 3958-3965.

[17] Shaw, J.L. and Diamandis, E.P. (2007) Distribution of 15 human kallikreins in tissues and biological fluids. Clinical Chemistry, 8, 1423-1432. http://dx.doi.org/10.1373/clinchem.2007.088104

[18] Diamandis, E.P., Borgoño, C.A., Scorilas, A., Yousef, G.M., Harbeck, N., Dorn, J., Schmalfeldt, B. and Schmitt, M. (2003) Immunofluorometric quantification of human kallikrein 5 expression in ovarian cancer cytosols and its association with unfavorable patient prognosis. Tumor Biology, 6, 299-309. http://dx.doi.org/10.1159/000076462

[19] Ekholm, I.E., Brattsand, M. and Egelrud, T. (2000) Stratum corneumtryptic enzyme in normal epidermis: A missing link in the desquamation process. Journal of Investigative Dermatology, 1, 56-63. http://dx.doi.org/10.1046/j.1523-1747.2000.00820.x

[20] Komatsu, N., Takata, M., Otsuki, N., Toyama, T., Ohka, R., Takehara, K. and Saijoh, K. (2003) Expression and localization of tissue kallikrein mRNAs in human epidermis and appendages. Journal of Investigative Dermatology, 3, 542-549. 
http://dx.doi.org/10.1046/j.1523-1747.2003.12363.x

[21] Caubet, C., Jonca, N., Brattsand, M., Guerrin, M., Bernard, D., Schmidt, R., Egelrud, T., Simon, M. and Serre, G. (2004) Degradation of corneodesmosome proteins by two serine proteases of the kallikrein family, SCTE/ KLK5/hK5 and SCCE/KLK7/hK7. Journal of Investigative Dermatology, 5, 1235-1244. http://dx.doi.org/10.1111/j.0022-202X.2004.22512.x

[22] Ishida-Yamamoto, A., Deraison, C. and Bonnart, C. (2005) LEKTI is localized in lamellar granules, separated from KLK5 and KLK7, and is secreted in the extracellular spaces of the superficial stratum granulosum. Journal of Investigative Dermatology, 2, 360-366. http://dx.doi.org/10.1111/j.0022-202X.2004.23583.x

[23] Bast, R.C., Hennessy, B. and Mills, G.B. (2009) The biology of ovarian cancer: New opportunities for translation. Nature Reviews Cancer, 6, 415-428. http://dx.doi.org/10.1038/nrc2644
[24] Jacobs, J. and Bast, R.C. (1989) The CA125 tumor associated antigen: A review of the literature. Human Reproduction, 4, 1-12.

[25] Borgoño, C.A. and Diamandis, E.P. (2004) The emerging roles of human tissue kallikreins in cancer. Nature Reviews Cancer, 11, 876-890. http://dx.doi.org/10.1038/nrc1474

[26] Dorn, J., Magdolen, V., Gkazepis, A., Gerte, T. and Harlozinska, A. (2011) Circulating biomarker tissue kallikrein-related peptidase KLK5 impacts ovarian cancer patients' survival. Annals of Oncology, 8, 1783-1790. http://dx.doi.org/10.1093/annonc/mdq701

[27] Bandiera, E., Zanotti, L., Bignotti, E., Romani, C., Tassi, R. and Todeschini, P. (2009) Human kallikrein 5 an interesting novel biomarker in ovarian cancer patients that elicits humoral response. International Journal of Gynecological Cancer, 6, 1015-1021. http://dx.doi.org/10.1111/IGC.0b013e3181ab597f 